Int. J. Morphol.,

28(3):765-770, 2010

\title{
Ginkgo biloba Effects on Mice Fetal Liver
}

\author{
Efectos de la Ginkgo biloba en el Hígado Fetal de Ratón
}

"Uruj Zehra; ${ }^{* *}$ Mohammad Tahir; ${ }^{* * *}$ Fahim H. Jaffery \& ${ }^{* * * *}$ Khalid P. Lone

ZEHRA, U.; TAHIR, M.; JAFFERY, F. H. \& LONE, K. P. Ginkgo biloba effects on mice fetal liver. Int. J. Morphol., 28(3):765-770, 2010.

SUMMARY: Ginkgo biloba is considered to be an alternative drug for various indications; unfortunately very few studies are available on its side effects. This present study describes the harmful effects of Ginkgo biloba on developing fetal liver. Two experimental groups of six pregnant female mice each were given Ginkgo biloba at human therapeutic dose (A) and a higher dose (B) throughout the gestation period. A third group $(\mathrm{C})$ was taken as a control and given distilled water only. Fetal livers were examined and the effects of the drug observed. There were signs of congestion and fatty change along with dilatation of sinusoids in a dose dependent manner concluding that Ginkgo biloba affects fetal liver.

KEY WORDS: Ginkgo biloba; Fetal liver; Congestion; Fatty change; Histology.

\section{INTRODUCTION}

Ginkgo biloba is a living fossil tree which changed little over 200 million years. It is widely cultivated in various parts of the world for its nuts and leaves. Its dried leaves extract containing mainly terpenoids and flavonoids have been used for 5000 years in traditional Chinese medicine for various purposes (Gold et al., 2002). Currently, Ginkgo extracts used for medicinal purposes are usually standardized to contain $24 \%$ ginkgo-flavone glycosides which are important antioxidants and $6 \%$ terpenoids having the property of antiplatelet activating factor (Oken et al., 1998). Previously it was popular only among old aged patients for various neurological symptoms especially related to Alzheimer's disease but now its popularity has increased due to its multiple indications such as peripheral vascular disease, age-related macular degeneration, vertigo, tinnitus, erectile dysfunction, and altitude sickness (Dubey et al., 2003). As the herbal medicines usually contain a range of pharmacologically active compounds, occasionally, it is not known which ingredients are important for the therapeutic effects. This is also true for Ginkgo biloba.

Ginkgo biloba is increasingly being used by the women of the child bearing age group; generally young women use this drug for memory enhancement, asthma, mountain sickness, varicose veins and for idiopathic cyclic edema. Its effectiveness during premenstrual syndrome has also been reported and is recommended by many health practitioners (Dugoua et al., 2006). Colchicine has been identified in the pooled placental blood of women using Ginkgo biloba as a dietary supplement and colchicine is known to inhibit normal cell division and has also been linked to Down's syndrome and therefore it is clearly contraindicated in pregnancy (Petty et al., 2001). The discovery of such a compound in the placental blood forced other scientists to think about the possible effects of Ginkgo biloba in pregnancy. Although women of different age groups are using it for various reasons, however, whether it is safe for pregnant and lactating mother is still controversial. Morphometric alterations were observed in the adult rat liver after the administration of Ginkgo biloba extract (Moreno et al., 2004). The present studies were undertaken because there are no reports available on the developmental effects of Ginkgo biloba. The present research was undertaken to find out if there is any developmental effect of Ginkgo biloba on developing fetal liver.

* Department of Anatomy, Wah Medical College, POF Hospital, Wah Cantt, Pakistan.

** Anatomy Department, University of Health Sciences Lahore, Pakistan.

**** Anatomy Department, Akhtar Saeed Hospital, Lahore, Pakistan.

${ }^{* * * * *}$ Wah University, The Mall,Wah Cantt, Pakistan. 


\section{MATERIAL AND METHOD}

Eighteen healthy female mice weighing 20-35 g were used in the experiment. They were acclimatized in the laboratory for 4-5 days under standard conditions of temperature and humidity. After mating the females with males at the ratio of three to one, the pregnant mice were separated and divided into three groups (A, B and C) of six mice each. The first two groups A and B were experimental while the $\mathrm{C}$ was control. Standardized extract of Ginkgo biloba was purchased from General Nutrition Centre laboratories (USA) in the form of capsules. The dose of Ginkgo biloba equivalent to human therapeutic dose was calculated to be $78 \mathrm{mg} / \mathrm{kg} / \mathrm{day}$ while high dose was $100 \mathrm{mg} /$ $\mathrm{kg} / \mathrm{day}$. Group A was given human therapeutic dose while group B was offered high dose throughout their gestational period. The mice were sacrificed on the $18^{\text {th }}$ day of gestation and fetuses were removed after splitting the uterine horns length wise. Each fetus was euthanized by hypothermia and decapitated. The abdominal viscera were exposed by mid line abdominal incision and liver was removed. The viscera were inspected for any visible deformity; color and consistency of the organs were checked and recorded. The fetal tissues were fixed in $10 \%$ buffered formalin for 72 hours, later they were processed in automatic tissue processor and embedded in paraffin. Labeled blocks were kept for fifteen minutes in freezer before cutting. Five micron thin sections were obtained using a rotary microtome (Leica RM 2125), floated in warm water at $450 \mathrm{C}$ and transferred to precleaned albumenized glass slides. Haematoxylin and eosin (H \& E) were used for general histology and periodic acid Schiff (PAS) technique was used for the demonstration of basement membranes. The sections were studied under a light microscope (Leica DM 1000). All measurements were made with a standardized ocular micrometer.

Statistical Analysis. The statistical analyses were carried out using SPSS version 13.0. The significance between means was calculated by the single factor ANOVA. Chi square was used for qualitative data. The difference was regarded significant if the 'p' value was $<0.05$.

\section{RESULTS}

Gross features. No gross discernable difference in shape, size and location was observed between the control and the treated groups.

\section{Histological Features}

Hepatocytes. The hepatocytes of high dose group B showed large empty spaces (Fig.1) within the cytoplasm indicative of drastic fatty degeneration which were not evident in control group (Fig. 2), fortyfour out of forty nine slides showed this change in the high dose group; the change was, however, less marked in group A, only twentysix out of fifty slides showed changes.

Fisher's Exact test showed that the difference of fatty change between groups $\mathrm{A}$ and $\mathrm{C}$ was statistically significant $(p<0.0001)$. However, the maximum degree of change was observed in the liver of group B as compared to that in groups $\mathrm{C}$ and $\mathrm{A}$. (Table I).

Hepatic sinusoids. Dilated sinusoids were seen in both the treated groups (Fig.3). ANOVA showed that there was a significant dose related increase in the size of the hepatic sinusoids of mice fetuses in A and B groups $(\mathrm{p}<0.001)$. Post-Hoc test, using the Tukey HSD (Table II), also showed that this difference was statistically significant ( $\mathrm{p}$ $<0.001$ ) among the $\mathrm{C}, \mathrm{A}$ and $\mathrm{B}$ groups.

Central Vein.There was dense infiltration of lymphocytes and nucleated RBCs around the central veins in the treated groups (Fig.4); nucleated RBCs were seen as dense collection in most of the central veins (Fig.5) showing congestion of liver. These factors were very prominent in group B. Forty six out of forty nine slides showed signs of congestion in group B. In group A, twenty five out of fifty slides showed congestive signs (Fig.6). Fisher's Exact test showed statistically significant difference $p<0.001$ (Table III).

Table I. Comparison of Fatty change in the Liver of the Fetuses among the Three Groups.

\begin{tabular}{cccc}
\hline \multirow{2}{*}{$\begin{array}{c}\text { Groups } \\
\text { Control(C) 49* }\end{array}$} & Groups Compared & Chi- square value & p- value \\
\cline { 2 - 4 } & Human therapeutic A group (50) & 31.92 & $<0.0001$ \\
\cline { 2 - 4 } Human therapeutic (A) 50* & High dose B group (49) & 76.26 & $<0.0001$ \\
\cline { 2 - 4 } *Fetuses in each group & High dose B group (49) & 15.3 & $<0.0001$ \\
\hline
\end{tabular}




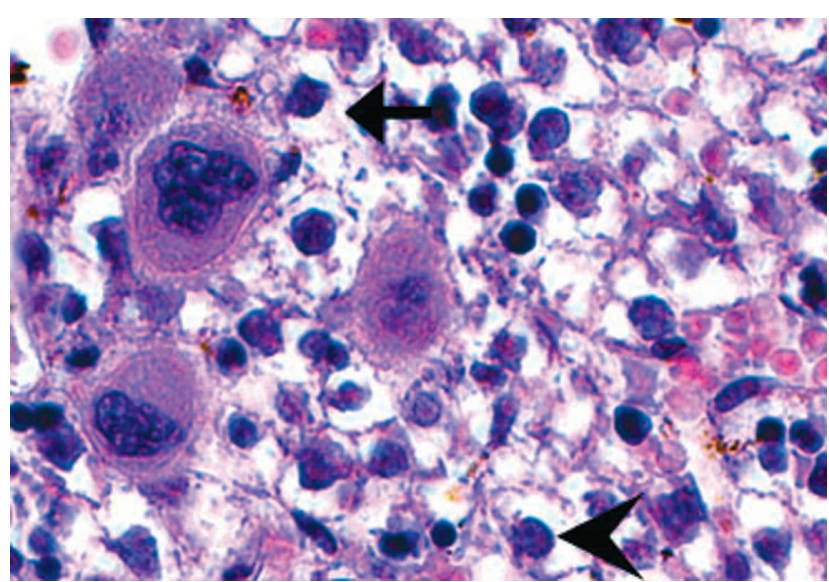

Fig. 1. Photomicrograph of fetal liver (Gp. B). Space (arrow) around the nuclei of hepatocytes (arrow head) suggesting fatty degeneration in the liver. Megakaryocytes with multilobed nuclei are seen, RBCs in sinusoids are also distinguished. H\&E. (X 400).

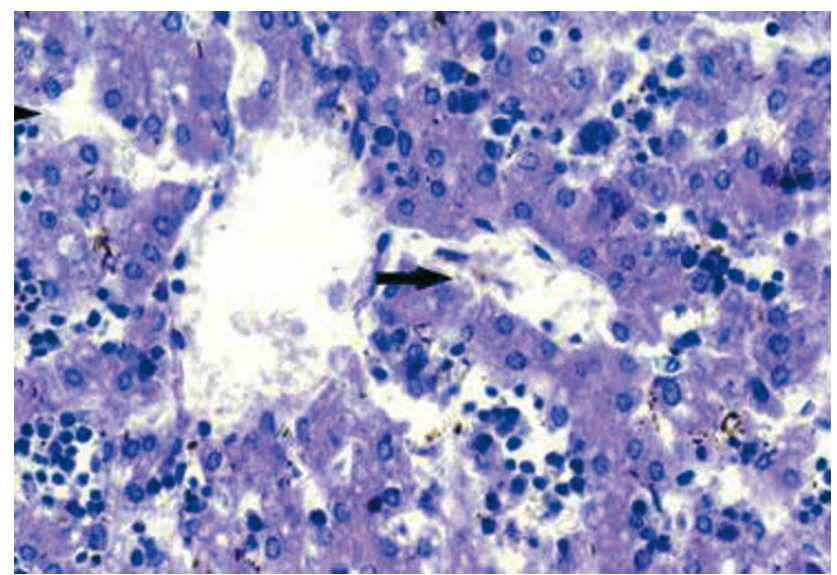

Fig. 3. Photomicrograph of fetal liver (Gp. A). Note the dilated sinusoids (arrow). Hematopoietic cells are seen within the sinusoids. H\&E. (X 200).

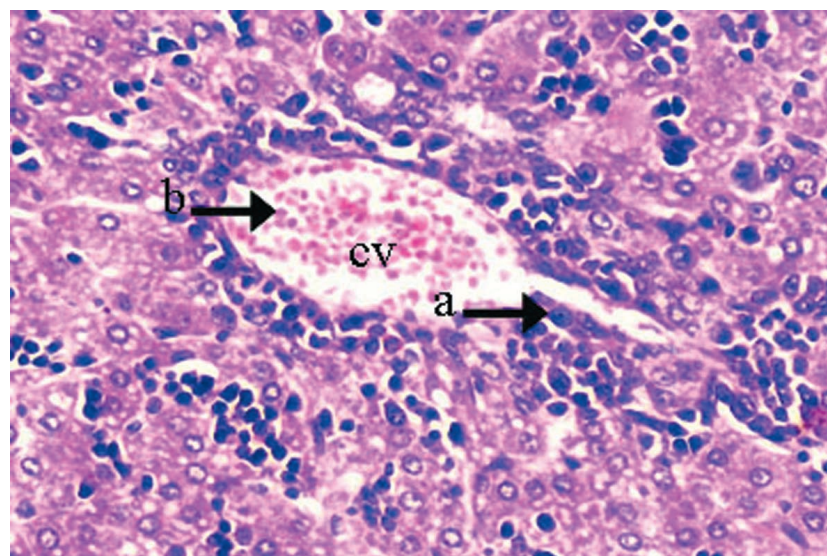

Fig. 5. Photomicrograph of fetal liver (Gp. A), showing continuation of sinusoidal capillaries (a) lined by squamous epithelium with central vein $(\mathrm{CV})$. Many nucleated RBCs (b) are present within the central vein. Hepatocytes are seen radiating from the central vein in the form of cords Abundant lymphocytes and few megakaryocytes are visible within the sinusoids. H\&E. (X 200).

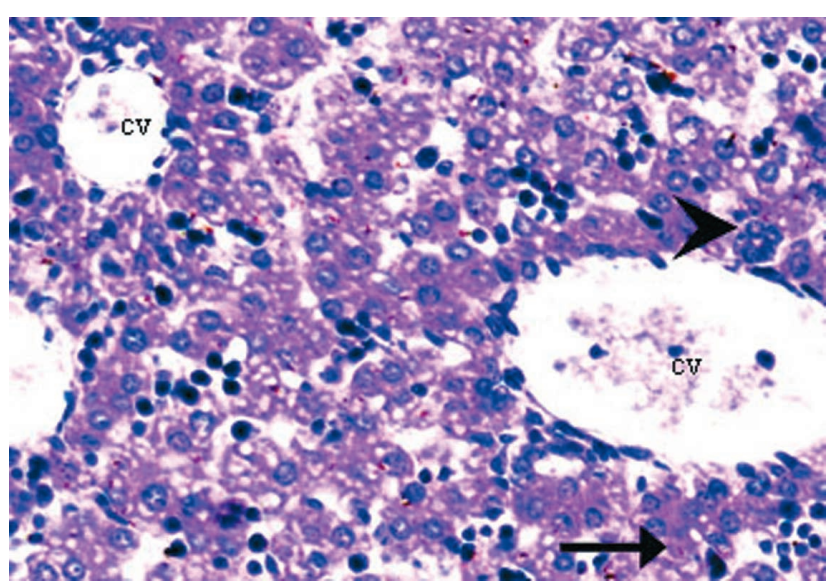

Fig. 2. Photomicrograph of fetal liver (Gp. C). The hepatocytes can be seen in the form of cords (arrow) and some hepatocytes form coherent groups (arrowhead), radiating from the central vein (CV) lined by squamous epithelium. Dark colored nuclei of hematopoietic cells are also seen in the sinusoids. H\&E. (X 200)

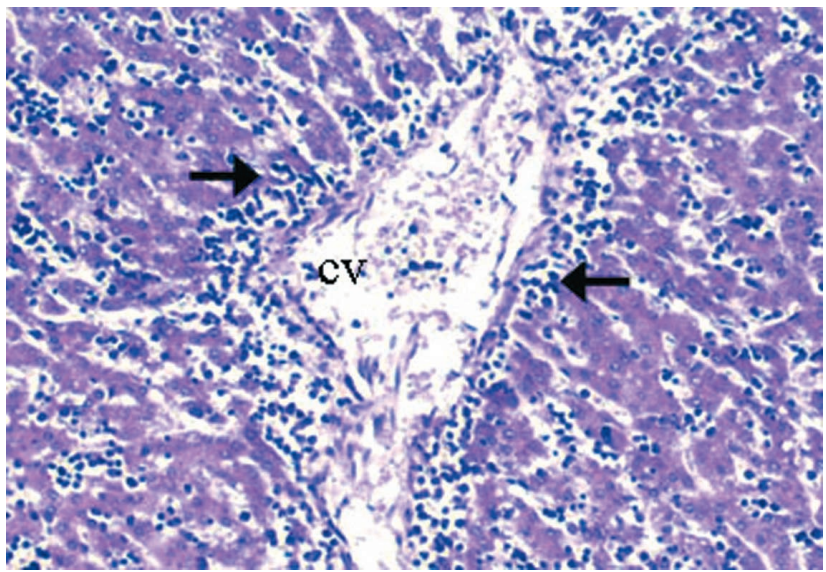

Fig. 4. Photomicrograph of fetal liver (Gp. A) Dense infiltration of hematopoietic cells, mostly lymphocytes, (arrow) around the central vein (CV). H\&E. (X 100).

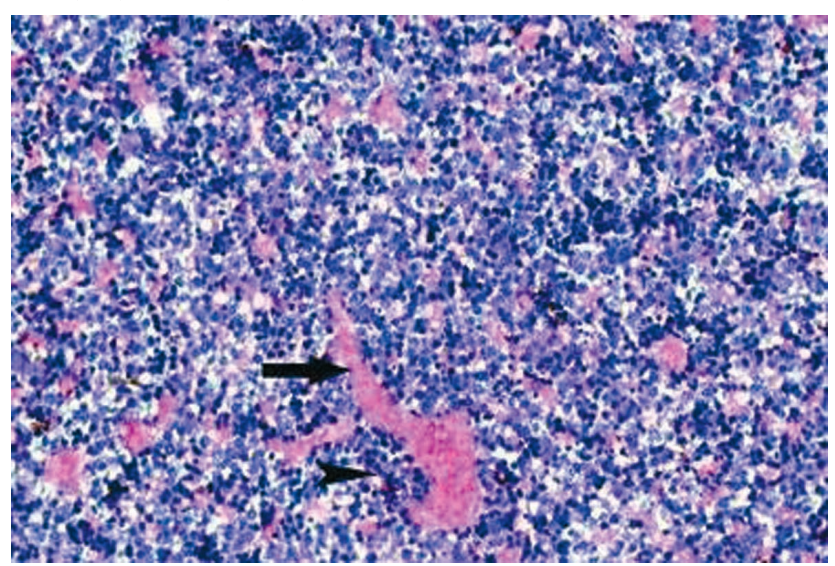

Fig. 6. Photomicrograph of fetal liver (Gp. B). The central veins (arrow) are surrounded by clusters of hepatocytes (arrowhead). The central veins and various sinusoids are congested with RBCs. The hexagonal arrangement is not discernable. Dark blue colored hematopoietic cells are seen within the sinusoids. H\&E. (X 100). 
Table II. Multiple Comparison of Size of Hepatic Sinusoids of the Fetuses among the Three Groups (A, B and C) according to the single classification ANOVA.

Comparison among groups

\begin{tabular}{llllll}
\hline \multirow{2}{*}{ Group (I) } & Group compared (J) & Mean Difference (I-J) & Std. Error (SE) & Level of Significance \\
\cline { 2 - 5 } Control (C) & Human therapeutic dose (A) & -3.29200 & 0.06159 & $<0.001$ \\
\cline { 2 - 5 } & High dose (B) & -7.23878 & 0.06190 & $<0.001$ \\
\hline \multirow{2}{*}{ Human therapeutic dose (A) } & Control (C) & 3.29200 & 0.06159 & $<0.001$ \\
\cline { 2 - 5 } & High dose (B) & -3.94678 & 0.06159 & $<0.001$ \\
\hline \multirow{2}{*}{ High dose (B) } & Control (C) & 7.23878 & 0.06190 & $<0.001$ \\
\cline { 2 - 5 } & Human therapeutic dose (A) & 3.94678 & 0.06159 & $<0.001$ \\
\hline
\end{tabular}

Table III. Comparison of Congestion of Liver in Fetuses among the Three Groups

\begin{tabular}{cccr}
\hline Groups & Groups Compared & Chi- square value & p-value \\
\hline \multirow{2}{*}{$\begin{array}{c}\text { Control(C) 49* } \\
\text { Human therapeutic (A) 50* }\end{array}$} & Human therapeutic A group (50) & 30.18 & $<0.0001$ \\
\cline { 2 - 4 } & High dose B group (49) & 82.96 & $<0.0001$ \\
\hline
\end{tabular}

*Fetuses in each group.

\section{DISCUSSION}

The histological observations on fetal liver preparations from both treated groups showed marked changes. Sign of congestion was seen in the central veins, sinusoids and hepatic parenchyma, this change was statistically significant in high dose treated group. In liver, nitric oxide (NO) synthesized by the endothelial NO synthase, regulates hepatic blood flow and vascular resistance and plays a significant role in stabilizing the hepatic microcirculation and protects the liver from oxidative injury (Nanji et al., 1995; Nishida et al., 1994; Wang \& Abdel Rahman, 2005). A previous study indicates that ginkgolide A, B and bilobalide may contribute to a selective inhibitory effect on iNOS expression via inhibiting nitric oxide synthase transcriptional activity (DeFeudis et al., 2003). A similar study had earlier revealed that following Ginkgo biloba extract treatment $(50 \mathrm{mg} / \mathrm{ml})$ there was a $30 \%$ reduction of NO metabolites released by the endothelial cells (Cheung et al., 1999); implying inhibition of NOS metabolites resulted in the sluggish blood flow to the liver producing congestion in the liver. Probably the inhibition of iNOS expression by Ginkgo biloba extract in a "dose dependant manner" explains the congestive liver in the fetuses. Whiting et al. (2002) reported $0.2-1 \%$ incidence of hepatotoxicity in their study on use of various Chinese herbal medicines in clinical trials containing mixture of alkaloids, tannins and terpenoids. In animal models diterpenoids had been shown to result in liver injury, either by reactive metabolites or by an autoimmune mechanism (Stedman, 2002). Since terpenoids are one of the main components of Ginkgo extract, this strengthens our results. Lontos et al. (2003) have reported the case of an acute liver failure in a woman using herbal preparation containing ginkgo extract. She underwent liver transplant surgery and examination of her explanted liver revealed hepatic damage showing severe necrosis. Hepatic damage caused in treated animals, in the present study, may be implied to have been caused by similar mechanism.

There were statistically significant findings of steatotic changes in the liver of treated groups in the present study. Ginkgo biloba extract contains 24\% phytoestrogens, their presence is the main reason for its use as a hormonal replacement therapy in a number of clinical conditions $(\mathrm{Oh}$ \& Chung, 2006). Farrell (2002) showed that the level of estrogens in the blood was one of the main reasons of druginduced steatosis in humans. The data of various studies, implicate estrogens as factor in the production of fatty liver syndrome. Information collected from the animal studies indicated that increase in plasma free fatty acids from estrogen treatment was suggestive of lipolytic action of the steroid and its role in the contribution of fatty liver development (Gruwmer et al., 1990; Polin \& Wolfor, 1997).

There was some evidence of harmful effects of phytoestrogens particularly on developmental stages in 
human fetuses. Animal studies provided evidence that during gestational, perinatal and neonatal periods, consumption of phytoestrogens had pharmacological effects, both acute and latent (Tuohy, 2003). Therefore, the presence of phytoestrogen component of Ginkgo was probably the cause of fatty liver in fetuses of high dose treated mothers.

The current study also showed that dilatation of sinusoidal spaces in the liver was dose related. This was similar to the histological observations reported by Moreno et al. (2004), on the liver of adult rats after administration of Ginkgo biloba extract. These workers administered the preparation of Ginkgo extract to female Wistar rats, and the organs were isolated after 6 days of treatment. Histological alterations were observed in the livers of the treated group.
The treated liver exhibited enlarged hepatocytes with abundant cytoplasmic contents and dilated hepatic sinusoidal spaces. These findings were not seen in the control liver. They explained these findings on the basis of the vasodilator and anticoagulant properties of metabolites of Ginkgo biloba extract (Moreno et al., 2004). It is, therefore, postulated that dilatation of sinusoidal spaces seen in the present study was on account of comparable reasons.

\section{CONCLUSION}

Our results indicate that Ginkgo biloba extract is deleterious to the developing fetus. There was no evidence from the previous studies suggesting its teratogenicity.

ZEHRA, U. TAHIR, M.; JAFFERY, F. H. \& LONE, K. P. Efectos de la Ginkgo Biloba en el hígado fetal de ratón. Int. J. Morphol., 28(3):765-770, 2010.

RESUMEN: La Ginkgo biloba es considerada, en varias indicaciones, como un medicamento alternativo; sin embargo, existen pocos reportes disponibles sobre sus efectos secundarios. Este estudio describe los efectos nocivos de Ginkgo biloba en el desarrollo del hígado fetal. Dos grupos experimentales de 6 ratones hembras preñadas recibieron Ginkgo biloba en la dosis terapéutica humana (A) y una dosis más alta (B) por el período de gestación. Un tercer grupo control (C) recibió agua destilada. Los hígados fetales fueron examinados y observados los efectos de la droga. Hubo signos de congestión y degeneración grasa, junto con la dilatación de sinusoides en función de la dosis. Como conclusión la Ginkgo biloba afecta el hígado fetal.

PALABRAS CLAVE: Ginkgo biloba; Hígado fetal; Congestión; Degeneración grasa; Histología.

\section{REFERENCES}

Cheung, F.; Siow, Y. L.; Chen, W. Z. \& O. K. Inhibitory effect of Ginkgo biloba extract on the expression of inducible nitric oxide synthase in endothelial cells. Biochem. Pharmacol., 58:1665-73, 1999.

DeFeudis, F. V.; Papadopoulos, V. \& Drieu, K. Ginkgo biloba extracts and cancer: a research area in its infancy. Fundam. Clin. Pharmacol., 17:405-17, 2003.

Dubey, A. K.; Shankar, P. R.; Upadhyaya, D. \& Deshpande, V. Y. Ginkgo biloba- an appraisal. Kathmandu Univ. Med. J., 2:225-9, 2004.

Dugoua, J. J.; Mills, E.; Perri, D. \& Koren, G. Safety and efficacy of ginkgo (Ginkgo biloba) during pregnancy and lactation. Can. J. Clin. Pharmacol., 13:277-84, 2006.

Farrell, G. C. Drugs and steatohepatitis. Semin. Liver Dis., 22:185-94, 2002.

Gold, P. E.; Cahill, L. \& Wenk, G.L. Ginkgo biloba: A
Cognitive Enhancer? Psychol. Sci. Pub. Interest, 3:2$11,2002$.

Grummer, R.; Bertics, S. J.; Lacount, D. W.; Snow, J. A.; Dentine, M. R. \& Stauffacher, R. H. Estrogen induction of fatty liver in dairy cattle. J. Dairy Sci., 73:1537-43, 1990.

Lontos, S.; Jones, R. M.; Angus, P. W. \& Gow, P. J. Acute liver failure associated with the use of herbal preparations containing black cohosh. Med. J. Aust., 179:390-1, 2003.

Moreno, S.; Carvalho, J. J.; Nascimento, A. L. R.; Freitas, R. S.; Diré, G. F.; Lima, E. A.; Lima-Filho, G. L.; Rocha, E. K. \& Bernardo-Filho, M. Biodistribution of sodium pertechnetate and light microscopy of organs isolated from the rats: Study of the effects of a Ginkgo biloba extract. Pak. J. Nutr., 3:64-7, 2004.

Nanji, A. A.; Greenberg, S. S.; Tahan, S. R.; Fogt, F.; Loscalzo, J.; Sadrzadeh, S. M.; Xie, J. \& Stamler, J. S. Nitric oxide production in experimental alcoholic liver 
disease in the rat: role inprotection from injury. Gastroenterology, 109:899-907, 1995.

Nishida, J.; McCuskey, R. S.; McDonnell, D. \& Fox, E .S. Protective role of NO in hepatic microcirculatory dysfunction during endotoxemia. Am. J. Physiol., 267:G1135-41, 1994.

Oh, S. M. \& Chung, K. H. Antiestrogenic activities of Ginkgo biloba extracts. J. Steroid. Biochem. Mol. Biol., 100:167-76, 2006.

Oken, B. S.; Storzbach, D. M. \& Kaye, J. A. The efficacy of Ginkgo biloba on cognitive function in Alzheimer disease. Arch. Neurol., 55:1409-15, 1998.

Petty, H. R.; Fernando, M.; Kindzelskii, A. L.; Zarewych, B. N.; Ksebati, M. B.; Hryhorczuk, L. M. \& Mobashery, S. Identification of colchicine in placental blood from patients using herbal medicines. Chem. Res. Toxicol., 14:1254-8, 2001.

Polin, D. \& Wolford, J. H. Role of estrogen as a cause of fatty liver hemorrhagic syndrome. J. Nutr., 107:873-86, 1977.

Stedman, C. Herbal hepatotoxicity. Semin. Liver Dis., 22:195-206, 2002.

Tuohy, P. G. Soy infant formula and phytoestrogens. $J$. Paediatr. Child Health, 39:401-5, 2003.

Wang, X. \& Abdel-Rahman, A. A. Effect of chronic ethanol administration on hepatic e NOS activity and its association with caveolin-1 and calmodulin in female rats. Am. J. Physiol. Gastrointest. Liver Physiol., 289:G579-85, 2005.

Whiting, P. W.; Clouston, A. \& Kerlin, P. Black cohosh and other herbal remedies associated with acute hepatitis. Med. J. Aust., 177:440-3, 2002.

\section{Correspondence to: \\ Dr. Uruj Zehra \\ Department of Anatomy \\ Wah Medical College \\ POF Hospital \\ Wah Cantt \\ PAKISTAN}

Email: zehra_dr@hotmail.com

Received: 19-05-2010

Accepted: 07-07-2010 